\title{
Ethik wird nicht einfacher
}

\section{Christina Aus der Au}

Prof. Dr. theol., Mitglied der Redaktion Ethik

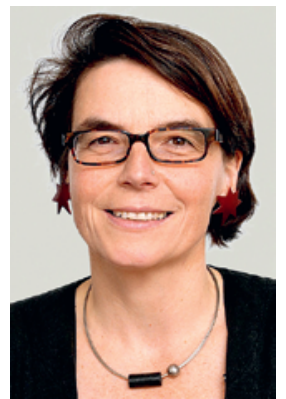

Nun lebt also der erste Mensch mit einem transplantierten Schweineherz in den USA. Ein Durchbruch für die Wissenschaft, ein Meilenstein, der Beginn einer neuen Ära, Hoffnung für tausende von Menschen, die auf Spenderorgane angewiesen sind - so klingen die Schlagzeilen! Und im Scheinwerferlicht steht neben den Ärztinnen und Ärzten der Patient: der 57-jährige Busfahrer David Bennett, der unter schweren Herzrhythmusstörungen litt und zum Schluss an die HerzLungen-Maschine angeschlossen werden musste. Er war so krank, dass er keine Chance hatte, auf die offizielle Transplantationsliste zu kommen. Seine erste Frage sei gewesen: «Werde ich dann grunzen?» Bennett taugt allerdings schlecht zum strahlenden Helden. Es stellte sich heraus, dass er vor über 30 Jahren wegen einer gewalttätigen Messerattacke zu einer mehrjährigen Haftstrafe verurteilt worden war. Die Familie des damaligen Opfers, das danach im Rollstuhl sass, meldete sich öffentlich zu Wort. Sie hätte sich einen würdigeren Empfänger gewünscht, liess die Schwester verlauten. Ihr Bruder sei nach 19 qualvollen Jahren gestorben, während sein Mörder nun eine zweite Chance erhalten würde.

Fachpersonen aus der Wissenschaft und Ethikerinnen und Ethiker wandten daraufhin ein, dass hier einzig und allein die Krankheitsgeschichte zählen dürfe. «We are not in the business of sorting sinners from saints", zitiert die britische Daily Mail den US-amerikanischen Bioethiker Arthur Caplan [1]. Legale Angelegenheiten müssten von medizinischen getrennt bleiben. Aber sind nicht «Sünder und Heilige» Begriffe aus einer anderen Schublade als derjenigen der Juristik? Muss man auch moralische Betrachtungsweisen von den medizinischen strikte trennen?

Nein, natürlich nicht! Dafür haben wir die Medizinethik in den meisten medizinischen Fakultäten und

Literatur

1 www.dailymail co.uk/news/article-10399737/Pigheart-transplantrecipient-stabbedman-seven-times 1988-leavingwheelchair-bound. html. Institutionen etabliert, welche solche Fragen im Umgang mit dem menschlichen Leben und Sterben reflektieren und begleiten. Jedes «heute kann man ...» kann hinterfragt werden mit «... aber soll man auch?».

Doch das mit der Ethik ist so eine Sache. Sie führt kaum je zu einfachen Antworten, sondern kompliziert die Dinge oft erst einmal.

So finde ich beides erst einmal sehr nachvollziehbar, das Entsetzen der Schwester und die ethische Argumentation. Ausgerechnet denjenigen Mann, der so viel Leid über die Familie gebracht hatte, hier zum Helden hochgejubelt zu sehen muss extrem unfair erscheinen. Hinzu kommt, dass sich diese Familie mit dem Geld, das für diese neunstündige Operation und die intensive Nachbegleitung investiert wird, wohl eine ganz andere Pflege für ihren am Schluss bettlägerigen Sohn und Bruder hätte leisten können.

Aber gleichzeitig würden sich Ärztinnen und Ärzte in des Teufels Küche begeben, wenn sie die moralische Würdigkeit ihrer Patientinnen und Patienten vor der Behandlung beurteilen müssten. Zudem stehen hinter diesem Mann weltweit tausende von verzweifelt auf Spenderorgane hoffenden Patientinnen und Patienten, für die solche Forschung ein Lichtblick bedeutet. Hat je jemand danach gefragt, ob der kleine James Phipps, der 1796 die erste Pockenimpfung erhielt, später auch zu einem anständigen Mitglied der Gesellschaft heranwuchs? Ich bin jedenfalls froh darüber, dass damit der Anfang gemacht war, um Krankheiten wie eben Pocken oder auch Polio auszurotten. Vielleicht ist dieses erste

\section{Das mit der Ethik ist so eine Sache. Sie führt} kaum je zu einfachen Antworten.

Schweineherz, das in einem Menschen schlägt, ebenso ein Anfang für eine Zukunft, in der Menschen nicht mehr sterben müssen, weil sie weiter unten auf einer Warteliste stehen. Dann würde in ferner Zukunft die Diskussion um Widerspruchs- oder Zustimmungslösung bei der Organspende vielleicht hinfällig. Aber dafür bleibt in naher Zukunft die Diskussion um Tier- und Menschenversuche umso brisanter. Das Schweineherz ist nicht einfach von einem einfachen Schwein gespendet worden. Dessen Genom wurde auf den Menschen hin modifiziert, und die Transplantation hat eine Geschichte von Schweineherztransplantationen in Paviane hinter sich. Diese überlebten dann zwischen Tagen und Monaten, je nachdem, wie immunsupprimiert ihr Körper anschliessend gehalten wurde. In den 80er Jahren war es auch einmal noch ein herzkrankes Baby, das seinerseits ein Pavianherz transplantiert erhielt. Sie war nicht die Erste, aber sie lebte anschliessend länger als ihre Vorgänger, nämlich noch drei Wochen. Ist es das das Hoffen und Leiden wert? Heute kann man - vielleicht. Soll man auch? Wer darf? Wer muss? Was wird daraus? Die Zukunftsdimension der Forschung miteinzubeziehen macht Ethik sicher nicht einfacher. Gerade deswegen bleibt die Diskussion unverzichtbar. 